\section{Planning globally}

There are plans for an international global research programme; its attainment will be difficult. EIGHTEEN months ago, the general assembly of the International Council of Scientific Unions (ICSU) at Ottawa considered several new schemes for collaborative research, of which the best-grounded was that for a study of phenomena that are intrinsically global. Among the cheer-leaders at Ottawa were Dr Herbert Friedman (best-known for having found celestial X-ray sources by the use of captured V-2 rockets) and Professor J.A. Eddy, who rediscovered the Maunder sunspot minimum of the seventeenth century. They have now persuaded the US National Academy of Sciences to publish* what amounts to a prospectus for their study, which is both interesting and literate.

The starting point is the International Geophysical Year, now remembered fondly not merely as a proof that collaboration can succeed but also as a time when governments would spend money on it. Those advocating the new study have ingeniously called it the International Geosphere-Biosphere Programme, which has the initials IGBP. The project is a programme in search of sponsors.

The case for doing something is compelling. The artfulness of the document, which has been prepared by the US committee for an IGBP (note the indefinite article) of which Eddy is the chairman, is that it concentrates on the unsolved problems that abound. Why is there so much less water in the stratosphere than one would expect? What happens to the carbon dioxide released from the surface of the Earth, from wood and forest fires as well as fossil fuel, that seems not to accumulate in the atmosphere even when allowance is made for solution in the oceans and for increasing biomass? The problem is partly the familiar difficulty of subtracting from each other two large uncertain numbers (for net release and net absorption by known sinks), but there must be some undiscovered sink to explain why as much as 2,000 million tonnes of carbon dioxide is lost each year. Then, separately, where does all the methane in the atmosphere come from? What, after decades of speculation on the subject, is the relationship (if any) between solar activity and climate?

That a coordinated attack on such questions would be worthwhile is hardly in dispute. The sales pitch judiciously steers away from some of the more obvious traps, that the programme might become stuck with acid rain to the exclusion of all else, for example. It is to be hoped that the document will be read sympathetically by those who will have to pay for it.

Why should they bother? It is not necessary to be fixated by the prospect of environmental doomsday to acknowledge that even the natural fluctuations of the physical environment revealed by the historical record are potentially, to make the very least of them, a great inconvenience to governments. The prospect of another glaciation in some thousands of years may be too distant to evoke budgets on the scale required, but mean sealevel changes such as those now apparently under way could easily cause trouble on a timescale not very different from that on which countermeasures would have to be planned. But the essence of the case for IGBP is that without an understanding of the natural fluctuations of the physical environment, we are all vulnerable to the unexpected.

So how should an IGBP be organized? The prospectus says that the new programme would coexist with international programmes already in being, the World Climate Research Programme for example, and would in no sense subsume them, which makes sense. But what is proposed would itself be a research programme with a timescale not very different from some of the global problems it would tackle. It would depend for its success on a continued and even accelerated flow of data from sources already active in the field, many of them controlled by governments. So an IGBP would have to be a long-term project, and one that was able effectively to stimulate research as well as helping to synthesize the data produced by others. A permanent international institute would almost certainly be less competent than existing laboratories working in parts of this huge field.

So why not aim at a radically different kind of international organization, one equipped with a small core of people with time to think and with funds sufficient to function internationally, as a foundation, making grants to people able and willing to fill obvious gaps in present understanding? The World Health Organisation's Special Programme of Research and Training in Tropical Diseases should be an encouraging model. The plain truth is that a project that is global in its essence deserves to be supported in a manner that is also global.

${ }^{*}$ Global Range in the Geosphere-Biosphere (National Academy Press, 1986).

\section{Overheads undermined}

The US government should think again about its scheme for cutting the cost of research grants.

THE research universities in the United States resist the use of the term "overhead" to describe the sums they receive from grant-making agencies in addition to the direct costs of successful research grant applications. The reason for this diffidence is obscure, but appears to derive from institutions' insistence that the "indirect costs" are real costs, those involved not merely in the administration of research grants but in the provision of that minimal support for research groups that will allow them to succeed in an increasingly fierce competition. But there are also suspicions that some universities fear that calling indirect costs overheads would lead to the fixing of uniform rate for all universities receiving grants instead of the present system in which different universities are differently rewarded.

This background has a bearing on the threat that now confronts the hundred or so research universities, the proposal of the Office of Management and Budget to amend the much derided circular A21 which regulates the way in which direct costs are accounted for and indirect costs determined. The intention is to fix a flat rate for the payment of indirect costs equal to the mean of the rates fixed in the past for different universities. Under the new arrangement, some will be better off, but because of a familiar statistical circumstance, most will be worse off. The explanation is merely that the universities traditionally more successful in the competition for research funds have also been those with the highest rate of reimbursement of indirect costs. Indeed, according to the draft of the amended regualtion now published in the Federal Register, the federal government hopes to save about $\$ 100$ million a year by this device.

University presidents are already up in arms about the issue, and rightly. Their circumstances are very different from those elsewhere, in most West European countries and even Japan, where governments recognize an obligation to support the infrastructure of research at universities. In the United States, state governments have in the past recognized such an obliga: tion, but there is no way in which the important private universities can be helped, unless from a levy on student's fees, except by federal support.

What is to be done? Universities will not serve their own interests if they protest too vigorously at the principle of uniformity, which offers at least an escape from the separate haggling over what the rate should be at different institutions. It would even be sensible that the universities now hoping to get the amendment changed in draft should offer to transfer from the direct to the indirect category of allowable costs some of the incidental spending (on travelling and publication, for example), which at present clutters up most research grant applications. But then the universities should insist that the rate which has been set is far too low. In Britain, the government reckons that 30 per cent of the recurrent cost of universities is for research (which amounts to roughly $£ 600$ million), while the direct cost of research grants to universities is less than half as much. $\square$ 